\title{
Clinical Characteristics in Patients Presenting with Red Eye
}

\author{
Müslüm Toptan ${ }^{1}$, Dursun Cadirci $^{1}$, and senay kocakoglu ${ }^{1}$ \\ ${ }^{1}$ Harran Universitesi
}

February 28, 2021

\begin{abstract}
Aim: Red eye, a frequent cause of presentations to ophthalmology clinics, is an important indicator of ocular inflammation. Although the prognosis is generally good and self-limiting, it is possible to distinguish possible serious conditions and prevent important situations such as blindness, with detailed examination and correct treatment approach. The purpose of this study was to evaluate patients with red eye presenting to the eye diseases clinic in terms of clinical and sociodemographic characteristics. Material-method: The records of patients presenting to the Şanlıurfa Harran University Hospital Ophthalmology Clinic with red eye were investigated retrospectively. Diseases causing red eye were classified according to the International Classification of Diseases (ICD 10) coding system. Demographic characteristics such as age and sex and clinical findings were examined. Results: A total of 2625 patients, 1775 males (67.61\%) and 850 females (32.38\%), who presented with red eyes, were evaluated. The incidence of viral conjunctivitis, the most frequently observed condition in patients presenting due to red eye, was $15.08 \%$ $(\mathrm{n}=396)$. The most common cause of red eye resulting in decreased vision and increased intraocular pressure (IOP) was acute angle closure glaucoma (AACG). The most common symptom was stinging-burning (70.36\%), and the most frequent finding was follicular hyperplasia $(74.17 \%)$. Five hundred and seventy-one $(21.75 \%)$ patients who applied to the clinic with red eye had previously applied to a family physician and 289 patients $(11.0 \%)$ to an emergency physician. Conclusion: Although prognosis is usually good in red eye, and the condition is self-limiting, the detection of serious conditions through a detailed history, examination, and therapeutic approach can be enhanced with early and appropriate intervention. In addition to family physicians and emergency physicians, the first to examine patients with red eye, important morbidities such as blindness can also be prevented by increasing the awareness of ophthalmologists and cooperation between these.
\end{abstract}

\section{Hosted file}

article 15.01.2021.pdf available at https://authorea.com/users/338733/articles/511272clinical-characteristics-in-patients-presenting-with-red-eye 